The following is the highest rated article in our 2019 submission category Future Health \& Society. All articles were ranked by HSI's independent professor judging panel. For this, the author was awarded one of three of HSI's annual "scholarship" awards.

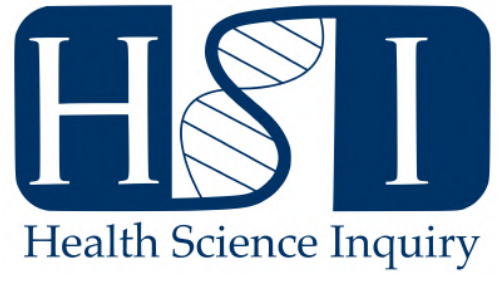

\title{
Healthcare in an Era of Patient Engagement: Language for Ongoing Dialogue
}

\author{
Umair Majid ${ }^{1}$ \\ ${ }^{1}$ Institute of Health Policy, Management, and Evaluation, University of Toronto
}

In the last century, we have observed a dramatic paradigm shift in the structure and function of society. Systems and political processes around the world have faced increasing demand by citizens to become active participants in public policy. Decisions made by the professional elite and the scientific truths that were unchallenged before, have become amenable to pressure and interrogation by citizens. This observation has transformed the healthcare system to involve patients, family, and care representatives as active participants in healthcare activities. Today, patient engagement (PE) occurs in an array of activities such as drug development, health system restructuring, hospital strategic planning, health technology assessment, and research. For example, hospitals have formed Patient and Family Advisory Committees that discuss organizational issues and quality improvement.

The practice of PE has, however, "jumped the gun" of its language and theory. There is a strong need for common language for discussing the methods and processes of $\mathrm{PE}$. This article summarizes some definitions, goals, benefits, mechanisms, and levels of PE. The information presented in this article provides a language for ongoing dialogue about the optimal approach and value of $\mathrm{PE}$ in healthcare.

\section{What is Patient Engagement?}

$\mathrm{PE}$ has many conceptualizations. PE comes from the literature on patient-centred care (PCC), a term that is in the healthcare vernacular today. PCC advances the notion that medical care and research evidence ought to be guided by patient preferences, perspectives, experiences, and needs [1]. However, PE is a broader concept than PCC; it refers to the mechanisms through which "patients can draw on their experience... and apply their priorities to the evaluation, development, organization and delivery of health services" [2]. There are two dimensions of PE: activities to improve their own care and the care of other patients. For example, patients can engage in their clinical care by using a tool to decide a treatment option that is aligned with their values, beliefs, and life plans. Patients can also engage in the planning of strategic hospital priorities, designing of care pathways, and patient safety initiatives that affect the care of other patients.

\section{ETHICAL IMPERATIVES AND SOCIAL AND Organizational Benefits}

$\mathrm{PE}$ is bolstered by ethical imperatives and social and organizational benefits. Ethical imperatives emerge from rights-based and consumerist modes of participation that empower "lay" people to engage into complex public policy processes. The effects of these imperatives are seen directly in the fields of social sciences and business. In healthcare, these imperatives have transformed the relationships between patients and professionals.

Benefits can be divided into those for patients and groups (e.g., interprofessional healthcare teams), and those for health service organizations. Examples of benefits include higher patient self-esteem [3], improved relationships between patients and healthcare providers [3], improved information for patients [4], the simplification of care processes and administrative structures of hospitals [4], and reduced hospital admissions [5]. The effects of not engaging patients in healthcare activities, however, has been less investigated than the benefits to engagement due to literature's infancy. One study found that not engaging patients may lead to adverse outcomes such as the widening of existing health disparities, the inefficient use of limited healthcare resources, and suboptimal health outcomes [6]. This area of the literature is promising for future research because it may help to anticipate the potential adverse consequences to patients and the healthcare system.

\section{ACTivities}

Patients engage in three categories of activities summarized in Table 1: clinical care, research, and organizational activities (e.g., designing, quality improvement). It should also be noted that there is an overlap between these activities. For example, patient safety initiatives that aim 
Table 1: Categories of patient engagement activities in health care.

\begin{tabular}{ll}
\hline Activity & Description \\
\hline Clinical Care & Engaging patients in their own care either by themselves or with the \\
& support and guidance from a licensed healthcare provider \\
Research & The design and conduct of research \\
Priority-Setting & Determining priorities for research, policy, or health care agendas \\
Organizational Activities & Planning, designing, delivery, evaluation \\
\hline
\end{tabular}

to reduce the transmission of in-hospital infections may be categorized under planning and designing, research, and evaluation.

\section{LEVELS}

Patients can also engage at different levels. The International Association of Public Participation (IAP2) spectrum comprises of five levels: inform, consult, involve, collaborate, and partner [7]. This framework is based on "ladders of participation," which indicate a tacit hierarchy between levels of engagement; in other words, partner is the "best" level of engagement. However, as other researchers have noted, ladders or hierarchies of engagement do not reflect $\mathrm{PE}$ practice, and may represent healthcare professionals' views of what engagement should look like [8]. Instead, different levels of engagement may be appropriate for distinct activities determined through communication with patients. Attempting to address this gap, Ontario's Patient Engagement Framework by Health Quality Ontario identifies four levels of PE: share, consult, deliberate, and collaborate [9]. Both of these frameworks are shown in Table 2 for comparison. Using these frameworks elucidates the role, purpose, and objectives of $\mathrm{PE}$ in a variety of contexts.

$\mathrm{PE}$ has become the expectation around the world in a variety of healthcare activities. The future of health systems will experience a greater integration of patients as decisionmakers and partners in interprofessional healthcare teams. This article briefly summarized the strong ethical imperatives and social and organizational benefits of $\mathrm{PE}$ and potential negative outcomes of not engaging patients. The information presented in this article provides a language for ongoing dialogue surrounding the optimal approach and value of $\mathrm{PE}$ in healthcare.

\section{REFERENCES}

[1] McCormack LA, Treiman K, Rupert D, WilliamsPiehota P, Nadler E, Arora NK, et al. Measuring patient-centered communication in cancer care: a literature review and the development of a systematic approach. Social science \& medicine. 2011;72(7):10851095.

[2] Tritter JQ. Revolution or evolution: the challenges of conceptualizing patient and public involvement in a consumerist world. Health Expectations. 2009;12(3):275-287.

[3] Hibbard JH, Greene J. What the evidence shows about patient activation: better health outcomes and care experiences; fewer data on costs. Health affairs. 2013;32(2):207-214.

[4] Crawford MJ, Rutter D, Manley C, Weaver T, Bhui K, Fulop N, et al. Systematic review of involving patients in the planning and development of health care. Bmj. 2002;325(7375):1263.

[5] Simpson EL, House AO. Involving users in the delivery and evaluation of mental health services: systematic review. Bmj. 2002;325(7375):1265.

[6] Gruman J, Rovner MH, French ME, Jeffress D, Sofaer $\mathrm{S}$, Shaller D, et al. From patient education to patient engagement: implications for the field of patient education. Patient education and counseling. 2010;78(3):350356.

[7] International Association for Public Participation. IAP2's Public Participation Spectrum; 2014. Available from: https://cdn.ymaws.com/www.iap2.org/ resource/resmgr/foundations_course/IAP2_P2_ Spectrum_FINAL.pdf.

[8] Johannesen J. Patient Views on "Ladders of Engagement". Toronto: Ontario SPOR Support Unit; 2018.

[9] Health Quality Ontario. Ontario's Patient Engagement Framework: creating a strong culture of patient engagement to support high quality health care. 2017; 
Table 2: A comparison of patient engagement frameworks by HQO and IAP2

\begin{tabular}{ll}
\hline HQO & IAP2 \\
\hline $\begin{array}{l}\text { Share: Provide easy-to- } \\
\text { understand health information }\end{array}$ & $\begin{array}{l}\text { Inform: Provide the public with balanced and objective information to assist them } \\
\text { in understanding the problem, alternatives, opportunities, and/or solutions }\end{array}$ \\
\hline $\begin{array}{l}\text { Consult: Get feedback on a } \\
\text { health issue }\end{array}$ & Consult: Obtain public feedback on analysis, alternatives and/or decisions \\
\hline $\begin{array}{l}\text { Deliberate: Discuss an issue } \\
\text { and explore solutions }\end{array}$ & $\begin{array}{l}\text { Involve: Work directly with the public throughout the process to ensure that } \\
\text { public concerns and aspirations are consistently understood and considered }\end{array}$ \\
\hline $\begin{array}{l}\text { Collaborate: Partner to ad- } \\
\text { dress an issue and apply solu- } \\
\text { tions }\end{array}$ & $\begin{array}{l}\text { Collaborate: Partner with the public in each aspect of the decision including } \\
\text { the development of alternatives and the identification of the preferred solution } \\
\text { Partner: Place final decision making in the hands of the public }\end{array}$ \\
\hline
\end{tabular}

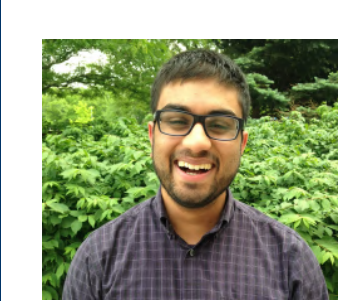

Umair Majid has a MSc in Health Research Methodology from McMaster University and MEd in Curricula Design from Queen's University. Currently, Umair is a Research Associate at University Health Network and PhD student in Health Services Management and Organization at University of Toronto. For his dissertation, Umair is investigating how to improve the mechanisms of patient engagement in hospital planning activities. 